\title{
Metais pesados e patógenos em milho e feijão caupi consorciados, adubados com lodo de esgoto
}

\author{
Thiago A. R. Nogueira ${ }^{1}$, Regynaldo A. Sampaio ${ }^{1}$, Ivana M. Fonseca ${ }^{1}$, Cleidson S. Ferreira ${ }^{1}$, \\ Sandra E. Santos ${ }^{2}$, Luiz C. Ferreira ${ }^{1}$, Eduardo Gomes ${ }^{1} \&$ Luiz A. Fernandes ${ }^{1}$
}

\begin{abstract}
RESUMO
Neste trabalho, buscou-se avaliar o efeito da adubação com lodo de esgoto submetido a diferentes processos de higienização, sobre os teores de metais pesados e densidade de patógenos no solo e em grãos de milho e feijão caupi consorciados. Os tratamentos no delineamento em blocos casualizados, com três repetições, corresponderam a: Solo sem adubação; Calagem e adubação química; Lodo não higienizado; Lodo higienizado com nim; Lodo higienizado com cal; Composto de lodo e ipomoea; Composto de lodo e ipomoea com fosfato; Lodo não higienizado e fosfato no solo; Lodo higienizado com nim e fosfato no solo; Lodo higienizado com cal e fosfato no solo; Composto de lodo e ipomoea e fosfato no solo. As densidades de patógenos no solo foram extremamente baixas e não diferiram entre tratamentos. As concentrações de metais pesados no solo, mesmo com uso do lodo de esgoto, não extrapolaram os limites máximos de adição anual nem os limites máximos permitidos para solos; apesar disso, as concentrações de Pb em grãos de milho, e de $\mathrm{Pb}$ e $\mathrm{Cr}$ em grãos de feijão, atingiram valores acima dos limites permitidos para produtos agrícolas, independente da adição de lodo ao solo. Em geral, não houve influência dos tipos de lodo de esgoto em relação aos teores de metais pesados, em grãos de milho e feijão.
\end{abstract}

Palavras-chave: adubo orgânico, biossólido, reciclagem de resíduos urbanos

\section{Heavy metals and pathogens in maize - cowpea intercropping system fertilized with sewage sludge}

\begin{abstract}
The objective of this work was to evaluate the effect of fertilization with sewage sludge submitted to different treatments of sanitization on contamination with heavy metals and pathogens in soil and grains of maize - cowpea intercropping system. The experimental design was completely randomized blocks with three replicates, corresponding to: soil without fertilization; liming and chemical fertilization; sewage sludge; sewage sludge sanitized with nim; sewage sludge sanitized with lime; composted sewage sludge and ipomoea; sewage sludge and ipomoea composted with rock phosphate; sewage sludge with rock phosphate incorporated in the soil; sewage sludge sanitized with nim and rock phosphate incorporated in the soil; sewage sludge sanitized with lime and rock phosphate incorporated in the soil; sewage sludge and ipomoea composted with rock phosphate incorporated in the soil. The pathogen density in the soil was extremely low and there were no differences between treatments. The heavy metal concentrations in the soil, including sewage sludge, did not surpass the maximum limits of annual addition and the permissible maximum limits for soils. In spite of this, the concentrations of $\mathrm{Pb}$ in maize grains, and $\mathrm{Pb}$ and $\mathrm{Cr}$ in cowpea grains, reached values above the limits permitted for agricultural products, independent of the addition of sewage sludge in the soil. In general, no influence of type of sewage sludge in relation to content of heavy metals in grains of corn and cowpea was observed.
\end{abstract}

Key words: organic fertilizers, biosolid, urban residues recycling 


\section{INTRODUÇÃO}

A utilização do lodo de esgoto na agricultura apresentase como tendência mundial; trata-se de uma técnica que consiste na disposição do lodo sobre o terreno, de modo a promover a melhoria das condições do solo ou do desenvolvimento da cobertura vegetal implantada, podendo ser utilizado, através da reciclagem, na agricultura, silvicultura, floricultura, paisagismo ou recuperação de áreas degradadas submetidas a processos de revegetação para recuperação (Silva et al., 2002).

De acordo com Nascimento et al. (2004), este resíduo contém considerável percentual de matéria orgânica e de elementos essenciais às plantas, podendo substituir, ainda que parcialmente, os fertilizantes minerais, e desempenhar importante papel na produção agrícola e na manutenção da fertilidade do solo.

No caso específico de lodos provenientes de reatores UASB, vislumbra-se a possibilidade de utilização do lodo seco ou úmido como condicionador de solos, desde que se tomem todos os cuidados necessários para evitar a contaminação do ambiente com patógenos. Segundo Lopes et al. (2005), os patógenos passíveis de serem encontrados no lodo se constituem em ovos de helmintos, cistos de protozoários, bactérias e vírus entéricos, em que as quantidades são dependentes da origem, da época do ano e do processo de tratamento ao qual o lodo foi submetido.

Outra limitação para o emprego do lodo de esgoto, é o aumento da disponibilidade e dos riscos de contaminação do solo com metais pesados (Lopes et al., 2005). Conforme Abreu et al. (1995) e Collier et al. (2004), a preocupação ambiental em relação às áreas em que os metais pesados se acumulam, tem aumentado, agravando-se o problema quando eles entram na cadeia alimentar; neste contexto, o conhecimento das formas químicas dos metais do solo permite melhor avaliação sobre a biodisponibilidade e mobilidade desses metais e seus riscos ao meio ambiente.

A acumulação de metais pesados nas plantas pode ocorrer sem que haja manifestação de sintomas de toxicidade e prejuízo na produção das culturas (Jeevan Rao \& Shantaran, 1996); este acúmulo afeta, sobremaneira, os microrganismos do solo (Valsecchi et al., 1995) e a qualidade dos alimentos (Soares et al., 2002); portanto, conhecer o destino desses elementos é essencial para a avaliação do impacto ambiental provocado pelo uso do lodo de esgoto no solo.

Dentre os processos de higienização do lodo para uso na agricultura, a caleação exerce significativa importância em razão do seu baixo custo, facilidade operacional e eficiência, além de agregar valor ao biossólido caracterizando-o como corretivo de acidez dos solos. A caleação, além de interferir na sobrevivência dos patógenos, tem-se mostrado eficiente na redução da absorção de metais pela cobertura vegetal, em razão da diminuição da disponibilidade desses elementos no solo (Martins et al., 2003).

Outra vantagem para o tratamento do lodo de esgoto é a compostagem, que se constitui em ótima alternativa de tratamento desses resíduos com finalidade agronômica, sendo que este processo permite o controle de microrganismos pa- togênicos e pode produzir um insumo agrícola de boa qualidade. A exemplo de outros materiais, os aspectos fundamentais para o processo, são: aeração, temperatura, umidade, relação C/N e tamanho das partículas (Costa et al., 2005).

Com o presente trabalho, objetivou-se avaliar os teores de metais pesados e de patógenos no solo e em grãos de milho e de feijão consorciados, adubados com diferentes tipos de lodo de esgoto.

\section{MATERIAL E MÉTODOS}

O experimento foi realizado na área experimental do Campus da UFMG, em Montes Claros, MG, em Cambissolo Háplico, cujas características químicas e físicas se acham na Tabela 1. Utilizaram-se, como plantas indicadoras em dois cultivos consecutivos, o milho crioulo CAA (Zea mays L.) e o feijão caupi (Vigna unguiculata (L.) Walp) consorciados.

O lodo de esgoto desidratado foi coletado na Estação de Tratamento de Esgoto - ETE, no município de Juramento, MG, operada pela Copasa, e a macrófita Ipomoea carnea ssp. fistulosa adquirida do reservatório do Sistema Verde Grande, onde se constitui em uma importante praga que onera os custos de manutenção do sistema de abastecimento de água da cidade de Montes Claros.

Tabela 1. Caracterização química e física ${ }^{(1)}$ do Cambissolo Háplico

\begin{tabular}{|c|c|}
\hline Atributos do solo & Valor \\
\hline pH em água & 5,40 \\
\hline P - Mehlich 1 (mg dm-3) & 4,20 \\
\hline $\mathrm{K}\left(\mathrm{mg} \mathrm{dm} \mathrm{d}^{-3}\right)$ & 76,00 \\
\hline $\mathrm{Ca}\left(\mathrm{cmol}_{\mathrm{c}} \mathrm{dm}^{-3}\right)$ & 4,10 \\
\hline $\mathrm{Mg}\left(\mathrm{cmol}_{\mathrm{c}} \mathrm{dm}^{-3}\right)$ & 1,50 \\
\hline $\mathrm{Al}\left(\mathrm{cmol}_{\mathrm{c}} \mathrm{dm}^{-3}\right)$ & 0,20 \\
\hline $\mathrm{H}+\mathrm{Al}\left(\mathrm{cmol}_{\mathrm{c}} \mathrm{dm}^{-3}\right)$ & 8,80 \\
\hline Soma de bases $\left(\mathrm{cmol}_{\mathrm{c}} \mathrm{dm}^{-3}\right)$ & 5,80 \\
\hline CTC efetiva $\left(\mathrm{cmol}_{\mathrm{c}} \mathrm{dm}^{-3}\right)$ & 6,00 \\
\hline Saturação de Al (\%) & 3,00 \\
\hline CTC total $\left(\mathrm{cmol}_{\mathrm{c}} \mathrm{dm}^{-3}\right)$ & 14,59 \\
\hline Saturação de bases (\%) & 40,00 \\
\hline Mat. Orgânica (dag kg-1) & 5,58 \\
\hline Areia (dag kg-1) & 40,00 \\
\hline Silte (dag kg-1) & 30,00 \\
\hline Argila (dag $\left.\mathrm{kg}^{-1}\right)$ & 30,00 \\
\hline
\end{tabular}

Logo após a aquisição dos materiais (lodo de esgoto e ipomoea) realizaram-se análises laboratoriais seguindo-se metodologias preconizadas por Tedesco et al. (1995): matéria orgânica, $\mathrm{pH}$, umidade, carbono e nitrogênio, tanto para o lodo quanto para a Ipomoea (Tabela 2); o carbono e o nitrogênio foram utilizados para se calcular a relação C/N com vistas à formação da compostagem.

A determinação inicial da concentração de coliformes totais e fecais no lodo de esgoto se deu pelo método do NMP e por meio da técnica de tubos múltiplos (ABNT, 1991). Os valores encontrados foram de 0,23 e 0,15 $\mathrm{NMP} \mathrm{g}^{-1}$, respectivamente, para coliformes totais e fecais; determinaram-se, 
Tabela 2. Caracterização química inicial das amostras de lodo de esgoto não higienizado e de ipomoea

\begin{tabular}{|c|c|c|c|c|c|}
\hline \multirow{2}{*}{ Materiais } & \multirow{2}{*}{$\mathrm{pH}-\mathrm{H}_{2} \mathrm{O}$} & \multirow{2}{*}{$\begin{array}{l}\text { Mat. Orgânica } \\
\text { g kg-1 }^{-1}\end{array}$} & $\mathbf{N}$ & C & Teor de água(1) \\
\hline & & & \multicolumn{3}{|c|}{ dag $\mathrm{kg}^{-1}$} \\
\hline Lodo de esgoto & 4,8 & 16,20 & 2,4 & 9,42 & 6,00 \\
\hline Ipomoea & 5,3 & 81,62 & 0,6 & 47,09 & 47,00 \\
\hline
\end{tabular}

também, as concentrações de ovos de helmintos viáveis e cistos de protozoários (Katz et al., 1972), não se detectando, no entanto, a presença desses parasitas no lodo de esgoto não higienizado.

A compostagem do lodo foi efetuada juntamente com a Ipomoea carnea ssp. fistulosa, triturada em desintegrador elétrico, tendo a meda altura de aproximadamente $1,5 \mathrm{~m}$; diariamente, monitorou-se a temperatura e o teor de água do material e se efetuou, sempre que necessário, o revolvimento manual das pilhas, por meio de pás e enxadas. A temperatura foi estimada com o auxílio de barras de ferro introduzidas na pilha de compostagem, em três pontos específicos do topo, do meio e da base, enquanto a umidade foi determinada pela secagem em estufa a $105^{\circ} \mathrm{C}$, até massa constante. Ao final do processo de degradação, o material foi estocado durante 30 dias, para maturação do composto.

O experimento constou de 11 tratamentos distribuídos no delineamento em blocos casualizados, com três repetições, conforme a seguir:

- $\mathrm{T}_{1}$ - Testemunha (solo sem adubação)

- $\mathrm{T}_{2}$ - Calagem $\left(3,65\right.$ t ha-1 de $\left.\operatorname{CaMg}\left(\mathrm{CO}_{3}\right)_{2}\right)$ e adubação química convencional $\left(575,66,7\right.$ e $500 \mathrm{~kg} \mathrm{ha}^{-1}$ de $\left(\mathrm{NH}_{4}\right)_{2} \mathrm{SO}_{4}, \mathrm{KCl}$ e $\mathrm{Ca}\left(\mathrm{H}_{2} \mathrm{PO}_{4}\right)_{2}$

- $\mathrm{T}_{3}$ - Aplicação de $16,7 \mathrm{tha}^{-1}$ de lodo de esgoto seco não higienizado

- $\mathrm{T}_{4}$ - Aplicação de $13,8 \mathrm{t} \mathrm{ha} \mathrm{a}^{-1}$ de lodo de esgoto seco higienizado com extrato de Nim

- $\mathrm{T}_{5}$ - Aplicação de $33,2 \mathrm{t} \mathrm{ha}^{-1}$ de lodo de esgoto seco tratado com cal virgem

- $\mathrm{T}_{6}$ - Aplicação de 28,1 t ha-1 composto orgânico feito com lodo de esgoto e Ipomoea

- $\quad \mathrm{T}_{7}$ - Aplicação de 30,6 t ha-1 composto orgânico feito com lodo de esgoto e Ipomoea mas com adição no início da compostagem, de $2 \%$ de fosfato natural reativo

- $\mathrm{T}_{8}$ - Aplicação de $14,1 \mathrm{t} \mathrm{ha}^{-1}$ de lodo de esgoto seco não higienizado + Aplicação no campo de $200 \mathrm{~kg} \mathrm{ha}^{-1}$ de fosfato natural reativo

- $\mathrm{T}_{9}$ - Aplicação de $13,1 \mathrm{tha}^{-1}$ de lodo de esgoto seco higienizado com extrato de Nim + Aplicação no campo de $200 \mathrm{~kg} \mathrm{ha}^{-1}$ de fosfato natural reativo
- $\mathrm{T}_{10}$ - Aplicação de 31,8 t ha-1 de lodo de esgoto seco tratado com cal virgem + Aplicação no campo de $200 \mathrm{~kg} \mathrm{ha}^{-1}$ de fosfato natural reativo

- $\mathrm{T}_{11}$ - Aplicação de 24,8 t ha-1 composto orgânico feito com lodo de esgoto e Ipomoea + Aplicação no campo de $200 \mathrm{~kg} \mathrm{ha}^{-1}$ de fosfato natural reativo

As variações nas dosagens do lodo foram estabelecidas conforme seu teor de água e na exigência de nitrogênio pela cultura do milho (115 kg ha-1 de $\mathrm{N}$ ), com base na disponibilidade deste elemento presente no lodo ou no composto de lodo e ipomoea; considerou-se, também, uma taxa de mineralização do material, da ordem de $50 \%$ ao ano (Moreira \& Siqueira, 2002).

Os tratamentos higienizados com Nim receberam meio litro de extrato aquoso de folhas de Nim, para cada litro de lodo de esgoto seco, enquanto os tratamentos higienizados com cal foram tratados na proporção de $50 \%$ da massa seca de lodo $+50 \%$ da massa seca de cal virgem, misturados a $70 \%$ de teor de água no lodo.

No tratamento com calagem e adubação química foram aplicados 3,65 t ha-1 de calcário dolomítico, para elevação da saturação de bases para 70\% e 575, 66,7 e $500 \mathrm{~kg} \mathrm{ha}^{-1}$ de sulfato de amônio, cloreto de potássio e superfosfato simples, respectivamente, com base na análise do solo e na recomendação de adubação para a cultura do milho.

As características químicas das diferentes formas de lodo de esgoto (tratamentos) utilizadas no experimento, são apresentadas na Tabela 3. Os teores totais dos nutrientes e metais pesados foram determinados no extrato ácido (ácido nítrico com ácido perclórico), conforme metodologia preconizada por Tedesco et al. (1995).

As características químicas dos fertilizantes e corretivos químicos utilizados no experimento, encontram-se na Tabela 4. Os teores de metais pesados foram determinados no extrato ácido (ácido nítrico com ácido perclórico), de acordo com a metodologia preconizada por Tedesco et al. (1995).

Tabela 4. Concentração de metais pesados nos fertilizantes e corretivos químicos utilizados no experimento

\begin{tabular}{lrrrrrr}
\hline \multirow{2}{*}{ Insumos } & $\mathbf{Z n}$ & $\mathbf{C u}$ & \multicolumn{1}{c}{$\mathbf{P b}$} & $\mathbf{C r}$ & $\mathbf{N i}$ & Cd \\
\cline { 2 - 7 } & & \multicolumn{5}{c}{ mg kg-1 $^{-1}$} \\
KCl & 116 & 11 & 7,65 & 3,55 & 1,60 & 0,40 \\
Super Simples & 201 & 30 & 2,05 & 50,60 & 11,80 & 6,10 \\
Sulfato de amônio & 383 & 21 & 4,30 & 250,70 & 15,10 & 45,50 \\
Calcário & 11 & 1 & 0,35 & 2,10 & 1,70 & 0,10 \\
Fosfato Natural & 35 & 5 & 8,60 & 8,25 & 2,60 & 0,20 \\
\hline
\end{tabular}

Tabela 3. Valor de pH e teores de nutrientes e de metais pesados nos materiais orgânicos utilizados nos tratamentos

\begin{tabular}{|c|c|c|c|c|c|c|c|c|c|c|c|c|c|c|c|}
\hline \multirow{2}{*}{ Tratamentos } & \multirow{2}{*}{$\mathrm{pH}-\mathrm{H}_{2} \mathrm{O}$} & $\mathbf{N}$ & $\mathbf{P}$ & K & $\mathrm{Ca}$ & $\mathrm{Mg}$ & $S$ & $\mathrm{Zn}$ & $\mathrm{Cu}$ & Cd & $\mathrm{Pb}$ & $\mathrm{Ni}$ & $\mathrm{Cr}$ & C.0. & $\mathrm{C} / \mathrm{N}$ \\
\hline & & \multicolumn{6}{|c|}{$\mathrm{mg} \mathrm{kg}^{-1}$} & \multicolumn{6}{|c|}{$\mu \mathrm{g} \mathrm{g}^{-1}$} & \multicolumn{2}{|c|}{$\%$} \\
\hline Lodo não higienizado & 4,40 & 10,4 & 2,9 & 5,8 & 7,0 & 3,2 & 11,5 & 302,0 & 71,0 & 0,1 & 56,9 & 29,5 & 46,7 & 6,55 & 6,29 \\
\hline Lodo + Nim & 4,75 & 7,8 & 3,0 & 5,6 & 6,5 & 3,0 & 9,2 & 319,0 & 76,0 & 0,1 & 60,1 & 30,9 & 56,6 & 7,02 & 9,00 \\
\hline Lodo + Cal & 12,02 & 14,0 & 1,7 & 4,0 & 146,6 & 2,6 & 6,3 & 187,0 & 36,0 & 0,0 & 27,7 & 20,1 & 27,5 & 3,74 & 2,67 \\
\hline Compostagem & 5,06 & 10,6 & 1,3 & 4,4 & 14,6 & 1,6 & 6,5 & 189,0 & 51,0 & 0,0 & 38,1 & 22,0 & 106,9 & 12,60 & 11,88 \\
\hline Compostagem + FN(1) & 4,56 & 10,9 & 3,7 & 5,8 & 18,5 & 2,2 & 6,1 & 228,0 & 55,0 & 2,3 & 44,8 & 24,0 & 116,6 & 12,00 & 11,00 \\
\hline
\end{tabular}


Realizou-se o primeiro cultivo das plantas no período de abril a setembro de 2004 e o segundo no período de janeiro a junho de 2005; cinco sementes de milho e duas de feijão foram semeadas por cova, e feito o desbaste após quinze dias, deixando-se apenas uma planta de milho e uma de feijão. $\mathrm{O}$ espaçamento utilizado para as culturas foi de $0,5 \mathrm{~m}$ entre plantas e de 1,0 m entre fileiras, em parcelas de $14 \mathrm{~m}^{2}$; cada parcela foi cultivada com 28 plantas de milho e 28 de feijão em consórcio na mesma cova, considerando-se bordaduras as fileiras externas.

Ao longo dos cultivos foram realizados tratos culturais com a aplicação de inseticida (STR0N, organofosforado sistêmico da agripec na quantidade de $25 \mathrm{~mL} 500 \mathrm{~m}^{-2}$ ), para o controle de Diabrotica speciosa, Cerotoma arcuata e Spodoptera frugiperda, tendo-se realizado duas aplicações. Utilizou-se um sistema fixo de irrigação por aspersão, constituído de duas linhas secundárias, com número total de seis aspersores e se adotou tanque Classe A para o manejo da irrigação; na área foram feitas capinas manuais sistemáticas.

As colheitas do feijão e do milho foram realizadas, respectivamente, aos 90 e 160 dias após o plantio, considerando-se o teor de água ideal para colheita de grãos, posteriormente ajustado para 13 dag $\mathrm{kg}^{-1}$.

Determinaram-se, nas amostras de solo coletadas na profundidade de 0 a $20 \mathrm{~cm}$, os teores disponíveis de $\mathrm{Zn}, \mathrm{Cu}$, $\mathrm{Pb}, \mathrm{Cr}$, Ni e Cd utilizando-se o extrator $\mathrm{HCl}$ 0,1M e, nos grãos de milho e de feijão, os teores de $\mathrm{Zn}, \mathrm{Cu}, \mathrm{Pb}, \mathrm{Cr}$, Ni e Cd, após digestão nítrico-perclórica (Tedesco et al., 1995); nessas amostras, foram determinadas, também, as concentrações de ovos de helmintos viáveis e cistos de protozoários (Katz et al., 1972) e coliformes totais e fecais (E. coli), pelo método do NMP, através da técnica de tubos múltiplos (ABNT, 1991).

Para cada variável estudada os dados obtidos foram submetidos à análise de variância e as médias comparadas até $5 \%$ de probabilidade, pelo teste de Scott-Knott.

\section{RESULTADOS E DISCUSSÃO}

A macrófita Ipomoea carnea ssp. fistulosa misturada ao lodo de esgoto, apresentou bons resultados na produção de composto orgânico, constituindo-se em uma importante fonte de adubo para uso agrícola, podendo ser explorada pela Copasa.

Nas análises iniciais do lodo de esgoto não higienizado, realizadas antes dos tratamentos, constatou-se ausência de verminoses (ovos de helmintos e cistos de protozoários), mas presença de coliformes totais e fecais com 0,23 e 0,15 NMP g-1. As densidades de coliformes fecais no lodo de esgoto permaneceram abaixo do limite crítico de $10^{3} \mathrm{NMP} \mathrm{g}^{-1}$ (Ferreira et al., 1999), demonstrando que, do ponto de vista microbiológico e parasitológico, este resíduo já poderia ser usado sem qualquer restrição, na agricultura.

Em relação a coliformes totais e fecais no solo, não houve diferença estatística entre os tratamentos aplicados (Tabela 5), mas se observa que até mesmo os tratamentos que não receberam lodo de esgoto apresentaram coliformes fecais no solo, possivelmente veiculados pela água de irrigação. De acordo com Soccol \& Paulino (2000) a densidade mínima de bactérias que pode causar infecção no homem é cerca de $10^{2}$ a $10^{6} \mathrm{NMP} \mathrm{g}^{-1}$, de forma que as densidades no solo podem ser consideradas muito baixas, não oferecendo maiores riscos à saúde humana. Resultados semelhantes a estes foram encontrados por Costa et al. (2001) ao constatarem, no solo incorporado com lodo de esgoto não higienizado, três meses após o plantio de mamoeiro, densidades de coliformes fecais abaixo de 0,02 $\mathrm{NMP} \mathrm{g}^{-1}$ e ausência de ovos de helmintos.

Tabela 5. Concentração de coliformes totais e fecais no solo, em função dos tratamentos

\begin{tabular}{|c|c|c|}
\hline Tratamento & $\begin{array}{l}\text { Coliformes Totais } \\
\left(\mathrm{NMP} \mathrm{g}^{-1}\right)\end{array}$ & $\begin{array}{l}\text { Coliformes Fecais } \\
(\text { NMP g-1) }\end{array}$ \\
\hline Solo sem adubação & $17,39 \mathrm{a}$ & $4,35 \mathrm{a}$ \\
\hline Calagem e adubação química & 53,33 a & $3,57 \mathrm{a}$ \\
\hline Lodo não higienizado & $16,52 \mathrm{a}$ & $4,35 \mathrm{a}$ \\
\hline Lodo higienizado com nim & $4,35 \mathrm{a}$ & $0,81 \mathrm{a}$ \\
\hline Lodo higienizado com cal & $0,00 \mathrm{a}$ & $0,00 \mathrm{a}$ \\
\hline Composto de lodo e ipomoea & $0,09 \mathrm{a}$ & $0,43 \mathrm{a}$ \\
\hline $\begin{array}{l}\text { Composto de lodo e ipomoea com } \\
\text { fosfato }\end{array}$ & $11,59 \mathrm{a}$ & $0,00 \mathrm{a}$ \\
\hline Lodo não higienizado e fosfato no solo & $102,26 \mathrm{a}$ & $0,20 \mathrm{a}$ \\
\hline $\begin{array}{l}\text { Lodo higienizado com nim e fosfato no } \\
\text { solo }\end{array}$ & $1,36 \mathrm{a}$ & $0,20 \mathrm{a}$ \\
\hline $\begin{array}{l}\text { Lodo higienizado com cal e fosfato no } \\
\text { solo }\end{array}$ & $31,97 \mathrm{a}$ & $1,25 \mathrm{a}$ \\
\hline $\begin{array}{l}\text { Composto de lodo e ipomoea e fosfato } \\
\text { no solo }\end{array}$ & 84,49 a & $0,00 \mathrm{a}$ \\
\hline
\end{tabular}

Médias seguidas da mesma letra na vertical não diferem estatisticamente entre si a 5\% de probabilidade pelo teste de Scott Knott

Com base nos dados apresentados na Tabela 6, vê-se que a maior contribuição em relação ao aporte de metais pesados ao solo foi do lodo de esgoto, comparado com os fertilizantes e corretivos químicos. Um aspecto relevante em relação à contribuição de metais pesados para o solo, foi a compostagem do lodo de esgoto com a ipomoea. Por se tratar de uma macrófita, a ipomoea absorve e acumula elevada quantidade de metais pesados presentes em meio aquático (Oliveira et al., 2001) o que contribuiu, sem dúvida, para o maior aporte desses elementos ao solo, com a aplicação do composto orgânico. Embora em menor quantidade, os fertilizantes e corretivos químicos também contribuíram para a contaminação do solo com metais pesados, conforme verificado também por Cravo et al. (1998), Malta (2001) e Campos et al. (2005). Considerando-se o caráter acumulativo dos metais pesados no solo, torna-se fundamental o cuidado com o uso sistemático desses fertilizantes na agricultura.

Com base nos dados apresentados na Tabela 7, nota-se que os teores disponíveis de $\mathrm{Cr}$ e $\mathrm{Ni}$ no solo não diferiram entre tratamentos; por outro lado, os teores de $\mathrm{Zn}$ e $\mathrm{Cu}$ foram, em geral, maiores nos tratamentos que receberam lodo de esgoto. Para $\mathrm{Zn}, \mathrm{Cu}, \mathrm{Pb}$ e $\mathrm{Cd}$, constatou-se menor disponibilidade com a adição de cal ao lodo, fato possivelmente relacionado aos maiores valores de $\mathrm{pH}$ proporcionado ao solo por esses tratamentos (Tabela 3). Segundo Melo et al. (2002), a elevação de pH do solo promove precipitação de 
Tabela 6. Aporte de metais pesados ao solo pelos fertilizantes orgânicos e químicos

\begin{tabular}{|c|c|c|c|c|c|c|c|}
\hline \multirow{2}{*}{ Tratamento } & \multirow{2}{*}{ Materiais } & $\mathrm{Zn}$ & $\mathrm{Cu}$ & $\mathrm{Pb}$ & $\mathrm{Cr}$ & $\mathrm{Ni}$ & Cd \\
\hline & & \multicolumn{6}{|c|}{$\mathrm{g} \mathrm{ha}^{-1}$} \\
\hline $\mathrm{T}_{1}$ & - & - & - & - & - & - & - \\
\hline \multirow{5}{*}{$\mathrm{T}_{2}$} & $\mathrm{KCl}$ & 7,74 & 0,73 & 0,51 & 0,24 & 0,10 & 0,02 \\
\hline & Super Simples & 100,50 & 15,00 & 1,02 & 25,30 & 5,90 & 3,05 \\
\hline & Sulfato de amônio & 220,22 & 12,07 & 2,47 & 144,15 & 8,68 & 26,16 \\
\hline & Calcário dolomítico & 40,15 & 3,65 & 1,28 & 7,66 & 6,20 & 0,36 \\
\hline & Total & 368,61 & 31,45 & 5,28 & 177,35 & 20,88 & 29,59 \\
\hline \multirow{3}{*}{$\mathrm{T}_{3}$} & Lodo não higienizado & $5.043,40$ & $1.185,70$ & 950,23 & 779,89 & 492,65 & 1,67 \\
\hline & Calcário dolomítico & 40,15 & 3,65 & 1,28 & 7,66 & 6,62 & 0,36 \\
\hline & Total & $5.083,55$ & $1.189,35$ & 951,51 & 787,55 & 498,85 & 2,03 \\
\hline \multirow{3}{*}{$\mathrm{T}_{4}$} & Lodo + Nim & $4.402,20$ & $1.048,80$ & 829,38 & 781,08 & 426,42 & 1,38 \\
\hline & Calcário dolomítico & 40,15 & 3,65 & 1,28 & 7,66 & 6,20 & 0,36 \\
\hline & Total & $4.442,35$ & $1.052,45$ & 830,66 & 788,74 & 432,62 & 1,74 \\
\hline \multirow{3}{*}{$T_{5}$} & Lodo + Cal & $6.208,40$ & $1.195,20$ & 919,64 & 913,00 & 667,32 & 0,00 \\
\hline & Calcário dolomítico & 40,15 & 3,65 & 1,28 & 7,66 & 6,20 & 0,36 \\
\hline & Total & $6.248,55$ & $1.198,85$ & 920,92 & 920,66 & 673,52 & 0,36 \\
\hline \multirow{3}{*}{$\mathrm{T}_{6}$} & Compostagem & $5.310,90$ & $1.433,10$ & $1.070,61$ & $3.003,89$ & 618,20 & 0,00 \\
\hline & Calcário dolomítico & 40,15 & 3,65 & 1,28 & 7,66 & 6,20 & 0,36 \\
\hline & Total & $5.331,05$ & $1.436,75$ & $1.071,89$ & $3.011,55$ & 624,40 & 0,36 \\
\hline \multirow{3}{*}{$\mathrm{T}_{7}$} & Compostagem $+\mathrm{FN}^{(1)}$ & $6.976,80$ & $1.683,00$ & $1.370,88$ & $3.567,96$ & 734,40 & 70,38 \\
\hline & Calcário dolomítico & 40,15 & 3,65 & 1,28 & 7,66 & 6,20 & 0,36 \\
\hline & Total & $7.016,95$ & $1.686,65$ & $1.372,16$ & $3.575,62$ & 740,60 & 70,74 \\
\hline \multirow{4}{*}{$\mathrm{T}_{8}$} & Lodo não higienizado & $4.258,20$ & $1.001,10$ & 802,29 & 658,47 & 415,95 & 1,41 \\
\hline & Fosfato Natural & 7,00 & 1,00 & 1,72 & 1,65 & 0,52 & 0,04 \\
\hline & Calcário dolomítico & 40,15 & 3,65 & 1,28 & 7,66 & 6,20 & 0,36 \\
\hline & Total & $4.305,35$ & $1.005,75$ & 805,29 & 667,78 & 422,67 & 1,81 \\
\hline \multirow{4}{*}{$\mathrm{T}_{9}$} & Lodo + Nim & $4.178,90$ & 995,60 & 787,31 & 741,46 & 404,79 & 1,31 \\
\hline & Fosfato Natural & 7,00 & 1,00 & 1,72 & 4,65 & 0,52 & 0,04 \\
\hline & Calcário dolomítico & 40,15 & 3,65 & 1,28 & 7,66 & 6,20 & 0,36 \\
\hline & Total & $4.226,05$ & $1.000,25$ & 790,31 & 750,77 & 11,51 & 1,71 \\
\hline \multirow{4}{*}{$\mathrm{T}_{10}$} & Lodo + Cal & $5.946,60$ & $1.144,80$ & 880,86 & 874,50 & 639,18 & 0,00 \\
\hline & Fosfato Natural & 7,00 & 1,00 & 1,72 & 1,65 & 0,52 & 0,04 \\
\hline & Calcário dolomítico & 40,15 & 3,65 & 1,28 & 7,66 & 6,20 & 0,36 \\
\hline & Total & $5.993,75$ & $1.149,45$ & 883,86 & 883,81 & 645,90 & 0,40 \\
\hline \multirow{5}{*}{$T_{11}$} & Compostagem & $4.687,20$ & $1.264,80$ & 944,88 & $2.651,12$ & 545,60 & 0,00 \\
\hline & Fosfato Natural & 7,00 & 1,00 & 1,72 & 1,65 & 0,52 & 0,04 \\
\hline & Calcário dolomítico & 40,15 & 3,65 & 1,28 & 7,66 & 6,20 & 0,36 \\
\hline & Total & $4.734,35$ & $1.269,45$ & 947,88 & $2.660,43$ & 552,32 & 0,40 \\
\hline & $\mathrm{MAA}^{(2)}$ & $30.000,00$ & $12.000,00$ & $15.000,00$ & $4.500,00$ & $3.000,00$ & 150,00 \\
\hline
\end{tabular}

$\mathrm{T}_{1}$ - Solo sem adubação; $T_{2}$ - Calagem e adubação química; $T_{3}$ - Lodo não higienizado; $T_{4}$ - Lodo higienizado com nim; $T_{5}$ - Lodo higienizado com cal; $T_{6}-$ Composto de lodo e ipomoea; $T_{7}-$ Composto de lodo e ipomoea com fosfato; $T_{8}$ - Lodo não higienizado e fosfato no solo; $T_{9}$ - Lodo higienizado com nim e fosfato no solo; $T_{10}$ - Lodo higienizado com cal e fosfato no solo; $T_{11}-$ Composto de lodo e ipomoea e fosfato no solo

(1) FN - Fosfato Natural

(2) Máxima adição anual permitida no solo, pela União Européia e Espanha (Berton, 2000)

metais pesados na forma de hidróxidos, fosfatos e carbonatos, e de complexos insolúveis com a matéria orgânica.

Conforme Bell et al. (1991), a aplicação anual prolongada de lodo de esgoto ao solo pode tornar-se restritiva ao sistema de produção agrícola, pelo enriquecimento de metais pesados no ambiente. Neste experimento observou-se que os teores de metais pesados no solo em todos os tratamentos, não extrapolaram os limites máximos de adição anual nem os limites máximos permitidos para solos, segundo a legislação européia. Resultados semelhantes foram encontrados por Rangel et al. (2004) e Trannin et al. (2005) na cultura do milho, e por Silva et al. (1998) na cultura de cana-de-açúcar.

Apesar dos teores disponíveis de $\mathrm{Ni}$ e Cd existentes no solo (Tabela 7), não se detectaram teores desses elementos nos grãos de milho nem de feijão. Pela Tabela 8 não se observa, nos grãos de milho, diferença estatística entre tratamentos para os teores de $\mathrm{Cu}$ e $\mathrm{Cr}$; por outro lado, o teor de Zn foi maior com a aplicação de composto de lodo e ipomoea mais a adição de fosfato natural no solo, enquanto o $\mathrm{Pb}$ foi, em geral, maior nos tratamentos contendo o lodo de esgoto associado ao fosfato natural. Nos grãos de feijão não houve diferença estatística entre tratamentos para nenhum dos metais pesados; dentre esses metais, apenas o $\mathrm{Pb}$, em grãos de milho, e $\mathrm{Pb}$ e $\mathrm{Cr}$, em grãos de feijão, superaram os teores toleráveis para produtos agrícolas. Acúmulos elevados de $\mathrm{Pb}$ em feijão-de-porco e em milho, também foram constatados por Pereira (2005); entretanto, a mobilidade e a disponibilidade de metais pesados no solo dependem da forma 
Tabela 7. Teores disponíveis de metais pesados no solo, em função dos tratamentos

\begin{tabular}{|c|c|c|c|c|c|c|}
\hline \multirow{2}{*}{ Tratamento } & $\mathrm{Zn}$ & $\mathrm{Cu}$ & $\mathrm{Pb}$ & $\mathrm{Cr}$ & $\mathrm{Ni}$ & $\mathrm{Cd}$ \\
\hline & \multicolumn{6}{|c|}{$\mathrm{mg} \mathrm{kg}^{-1}$} \\
\hline Solo sem adubação & $1,20 \mathrm{c}$ & $1,97 \mathrm{a}$ & $2,52 \mathrm{a}$ & $0,60 \mathrm{a}$ & $0,35 \mathrm{a}$ & $0,00 \mathrm{~b}$ \\
\hline Calagem e adubação química & $2,56 \mathrm{c}$ & $1,47 \mathrm{~b}$ & 1,89 a & $0,65 \mathrm{a}$ & $0,45 \mathrm{a}$ & $0,02 b$ \\
\hline Lodo não higienizado & $7,90 \mathrm{a}$ & $2,20 \mathrm{a}$ & $2,37 \mathrm{a}$ & $0,58 \mathrm{a}$ & $0,68 \mathrm{a}$ & $0,00 \mathrm{~b}$ \\
\hline Lodo higienizado com nim & $7,97 \mathrm{a}$ & $2,80 \mathrm{a}$ & $3,40 \mathrm{a}$ & $0,43 \mathrm{a}$ & $0,61 \mathrm{a}$ & $0,01 \mathrm{~b}$ \\
\hline Lodo higienizado com cal & $5,67 \mathrm{~b}$ & $1,13 \mathrm{~b}$ & $0,48 \mathrm{~b}$ & $0,85 \mathrm{a}$ & $0,40 \mathrm{a}$ & $0,01 \mathrm{~b}$ \\
\hline Composto de lodo e ipomoea & $6,63 \mathrm{a}$ & $2,30 \mathrm{a}$ & $2,51 \mathrm{a}$ & $0,44 \mathrm{a}$ & $0,56 \mathrm{a}$ & $0,01 \mathrm{~b}$ \\
\hline Composto de lodo e ipomoea com fosfato & $8,17 \mathrm{a}$ & $2,23 \mathrm{a}$ & $2,29 \mathrm{a}$ & $0,75 \mathrm{a}$ & $0,65 \mathrm{a}$ & $0,04 \mathrm{a}$ \\
\hline Lodo não higienizado e fosfato no solo & $10,27 \mathrm{a}$ & $2,70 \mathrm{a}$ & $3,06 \mathrm{a}$ & $0,62 \mathrm{a}$ & $0,76 \mathrm{a}$ & $0,03 \mathrm{a}$ \\
\hline Lodo higienizado com nim e fosfato no solo & $9,80 \mathrm{a}$ & $2,50 \mathrm{a}$ & $2,28 \mathrm{a}$ & $0,54 \mathrm{a}$ & $0,67 \mathrm{a}$ & $0,04 \mathrm{a}$ \\
\hline Lodo higienizado com cal e fosfato no solo & $4,27 \mathrm{~b}$ & $0,97 \mathrm{~b}$ & $0,04 \mathrm{~b}$ & $0,81 \mathrm{a}$ & $0,38 \mathrm{a}$ & $0,00 \mathrm{~b}$ \\
\hline Composto de lodo e ipomoea e fosfato no solo & $5,73 \mathrm{~b}$ & $1,90 \mathrm{a}$ & $1,98 \mathrm{a}$ & $0,52 \mathrm{a}$ & $0,52 \mathrm{a}$ & $0,02 \mathrm{~b}$ \\
\hline LMP(1) & $150-300$ & $50-140$ & $50-300$ & $100-150$ & $30-75$ & $1-3$ \\
\hline
\end{tabular}

(1) Limite máximo permitido no solo pela União Européia (Ferreira et al., 1999)

Médias seguidas da mesma letra na vertical não diferem estatisticamente entre si a $5 \%$ de probabilidade pelo teste de Scott Knott

química sob a qual o metal se apresenta e de características do solo como $\mathrm{pH}$, teor de matéria orgânica, CTC e percentagem de argila (Mulchi et al., 1991); neste caso, e dependendo das circunstâncias, mesmo com a aplicação de doses elevadas de lodo de esgoto pode haver pouca absorção e acúmulo de metais pesados na planta (Nascimento et al., 2004). De qualquer forma, ficou evidente que o lodo de esgoto não contribuiu para a contaminação de grãos de milho nem de feijão com metais pesados.

Os teores de $\mathrm{Pb}$ e Cr em grãos de milho e de feijão acima dos níveis permitidos (Tabela 8), mesmo com a máxima adição anual e com os teores no solo dentro dos limites permitidos (Tabelas 6 e 7), evidenciam a necessidade de se estabelecer cargas anuais e teores de metais no solo para as condições tropicais, de forma a se ter maior precisão em relação aos riscos de absorção desses elementos pelas plantas e de entrada na cadeia alimentar. Conforme Pires et al. (2005), levando-se em consideração as condições de acidez de grande parte dos nossos solos, concluiu-se que não há, ainda, resultados definitivos em relação à previsão de fitodisponibilidade de metais pesados, possivelmente pelo fato dos extratores não simularem as reações que ocorrem próximo às raízes.

Os valores médios de metais pesados em feijão foram superiores àqueles encontrados no milho (Tabela 8), fato este que pode estar relacionado à maior acidez normalmente verificada na rizosfera das leguminosas, o que favorece a disponibilidade e absorção desses elementos. De acordo com Helyar (1976), Ascencio \& Lazo (2001) e Pires (2005), além de outros mecanismos que envolvem a liberação de íons hidrogênio na rizosfera, a maior absorção de cátions que de ânions pelas plantas fixadoras de nitrogênio, reduz o pH do ambiente radicular, sendo necessários $250 \mathrm{~kg} \mathrm{ha}^{-1}$ de calcário para manter o $\mathrm{pH}$ inalterado em um solo de baixo poder tampão, para cada $70 \mathrm{~kg} \mathrm{ha}^{-1}$ de nitrogênio fixado biologicamente.

\section{CONCLUSÕES}

1. As densidades de coliformes fecais e parasitas no solo foram extremamente baixas, mesmo com a adição de lodo

Tabela 8. Teores de metais pesados em grãos de milho e feijão, em função dos tratamentos

\begin{tabular}{|c|c|c|c|c|c|c|c|c|}
\hline \multirow{3}{*}{ Tratamentos } & \multicolumn{4}{|c|}{ Milho } & \multicolumn{4}{|c|}{ Feijão } \\
\hline & $\mathrm{Zn}$ & $\mathrm{Cu}$ & $\mathrm{Pb}$ & $\mathrm{Cr}$ & Zn & $\mathrm{Cu}$ & $\mathrm{Pb}$ & $\mathrm{Cr}$ \\
\hline & \multicolumn{8}{|c|}{$\mathrm{mg} \mathrm{kg}^{-1}$} \\
\hline Solo sem adubação & $22,67 \mathrm{~b}$ & $1,70 \mathrm{a}$ & $15,00 \mathrm{~b}$ & $1,50 \mathrm{a}$ & $51,67 \mathrm{a}$ & $9,00 \mathrm{a}$ & $28,70 \mathrm{a}$ & $3,15 \mathrm{a}$ \\
\hline Calagem e adubação química & $24,00 \mathrm{~b}$ & $1,30 \mathrm{a}$ & $12,03 \mathrm{~b}$ & $1,50 \mathrm{a}$ & $46,33 \mathrm{a}$ & $8,34 \mathrm{a}$ & $20,32 \mathrm{a}$ & $3,33 \mathrm{a}$ \\
\hline Lodo não higienizado & $26,67 \mathrm{~b}$ & $1,70 \mathrm{a}$ & $15,90 \mathrm{~b}$ & $1,80 \mathrm{a}$ & $47,60 \mathrm{a}$ & $8,67 \mathrm{a}$ & $33,61 \mathrm{a}$ & $3,45 \mathrm{a}$ \\
\hline Lodo higienizado com nim & $28,34 \mathrm{~b}$ & $1,70 \mathrm{a}$ & $30,31 \mathrm{~b}$ & $1,60 \mathrm{a}$ & $49,33 \mathrm{a}$ & $9,34 \mathrm{a}$ & $69,32 \mathrm{a}$ & $3,68 \mathrm{a}$ \\
\hline Lodo higienizado com cal & $27,68 \mathrm{~b}$ & $1,70 \mathrm{a}$ & $17,74 \mathrm{~b}$ & $1,50 \mathrm{a}$ & $49,00 \mathrm{a}$ & $8,67 \mathrm{a}$ & $44,90 \mathrm{a}$ & $3,38 \mathrm{a}$ \\
\hline Composto de lodo e ipomoea & $31,00 \mathrm{~b}$ & $2,00 \mathrm{a}$ & $16,48 \mathrm{~b}$ & $1,80 \mathrm{a}$ & $48,33 \mathrm{a}$ & $8,67 \mathrm{a}$ & 30,51 a & $3,20 \mathrm{a}$ \\
\hline Composto de lodo e ipomoea com fosfato & $27,00 \mathrm{~b}$ & $1,30 \mathrm{a}$ & $38,15 \mathrm{a}$ & $1,60 \mathrm{a}$ & 49,67 a & $8,34 \mathrm{a}$ & 25,56 a & $3,31 \mathrm{a}$ \\
\hline Lodo não higienizado e fosfato no solo & $32,67 \mathrm{~b}$ & $2,30 \mathrm{a}$ & $64,60 \mathrm{a}$ & $1,80 \mathrm{a}$ & 50,67 a & $8,34 \mathrm{a}$ & $12,33 \mathrm{a}$ & $2,92 \mathrm{a}$ \\
\hline Lodo higienizado com nim e fosfato no solo & $30,34 \mathrm{~b}$ & $2,00 \mathrm{a}$ & $44,95 \mathrm{a}$ & $1,30 \mathrm{a}$ & $50,00 \mathrm{a}$ & $9,00 \mathrm{a}$ & $27,26 \mathrm{a}$ & $3,03 \mathrm{a}$ \\
\hline Lodo higienizado com cal e fosfato no solo & $32,67 \mathrm{~b}$ & $2,00 \mathrm{a}$ & $15,72 b$ & $1,80 \mathrm{a}$ & $46,33 \mathrm{a}$ & $8,34 \mathrm{a}$ & $26,45 \mathrm{a}$ & $3,19 \mathrm{a}$ \\
\hline Composto de lodo e ipomoea e fosfato no solo & $48,00 \mathrm{a}$ & $1,50 \mathrm{a}$ & $23,53 \mathrm{~b}$ & $1,70 \mathrm{a}$ & $49,00 \mathrm{a}$ & $8,67 \mathrm{a}$ & $30,43 a$ & $3,33 \mathrm{a}$ \\
\hline Limite ${ }^{(1)}$ & 300,00 & 150,00 & 10,00 & 2,00 & 300,00 & 150,00 & 10,00 & 2,00 \\
\hline
\end{tabular}

(1) Teores de metais pesados toleráveis em produtos agrícolas (Sopper, 1993)

Médias seguidas da mesma letra na vertical não diferem estatisticamente entre si a 5\% de probabilidade pelo teste de Scott Knott 
de esgoto não higienizado, o que o torna, do ponto de vista sanitário, apropriado para uso agrícola.

2. As concentrações de metais pesados no solo não extrapolaram os limites máximos de adição anual nem os limites máximos permitidos para solos, conforme legislação estabelecida para a Europa.

3. A adição ao solo de lodo de esgoto tratado com cal diminuiu, de modo geral, os teores disponíveis de metais pesados no solo.

4. As concentrações de $\mathrm{Pb}$, em grãos de milho, e de $\mathrm{Pb}$ e Cr, em grãos de feijão, ultrapassaram os limites toleráveis para produtos agrícolas independente da adição de lodo de esgoto ao solo.

5. Em geral, não houve influência dos tipos de lodo de esgoto em relação aos teores de metais pesados, em grãos de milho e feijão.

\section{AGRADECIMENTOS}

Os autores expressam seus maiores agradecimentos à Fundação de Amparo a Pesquisa de Minas Gerais - Fapemig pelo apoio financeiro que possibilitou a realização deste trabalho.

\section{LITERATURA CITADA}

ABNT - Associação Brasileira de Normas Técnicas. Bactérias coliformes totais, coliformes fecais e Escherichia coli em alimentos: determinação do número mais provável (NMP): MB3463. Rio de Janeiro, 1991. 7p.

Abreu, C. A.; Abreu, M. F.; Raij, B. V.; Santos, W. R. Comparação de métodos para avaliar a disponibilidade de metais pesados. Revista Brasileira de Ciência do Solo, Campinas, v.19, n.3, p.463-465, 1995.

Ascencio, J.; Lazo, J. V. Crecimiento y eficiencia de fósforo de algunas leguminosas cultivadas en arena regada con soluciones nutritivas con fosfatos inorgánicos de hierro y calcio. Revista de la Facultad de Agronomía (LUZ), Maracaibo, v.18, n.1, p.13-32, 2001.

Bell, P. F.; James, B. R.; Chaney, R. L. Heavy metal extractability in long-term sewage sludge and metal salt-amended soils. Journal of Enviromental Quality, Madison, v.20, p.481486, 1991.

Berton, R. S. Riscos de contaminação do agroecossitema com metais pesados. In: Bettiol, W.; Camargo, O. A. Impacto ambiental do uso agrícola do lodo de esgoto. Jaguariúna: Embrapa Meio Ambiente, 2000.cap.16, p.259-268.

Campos, M. L.; Silva, F. N. da; Furtini Neto, A. E.; Guilherme, L. R. G.; Marques, J. J.; Antunes, A. S. Determinação de cádmio, cobre, cromo, níquel, chumbo e zinco em fosfatos de rocha. Pesquisa Agropecuária Brasileira, Brasília, v.40, n.4, p.361-367, 2005.

Collier, L. S.; Sobrinho, N. M. B. do A.; Mazur, N.; Velloso, A. C. X. Efeito do composto de resíduo sólido urbano no teor de metais pesados em solo e goiabeira. Bragantina, Campinas, v.63, n.3, p.567-574, 2004.
Costa, A. N. da; Costa, A. F. S. da; Marques, M. O.; Santana, R. C. Estudo de caso - utilização de lodo de estações de tratamento de esgoto (ETEs) na cultura do mamoeiro no Norte do Estado do Espírito Santo. In: Andreoli, C.V. (Coord.). Resíduos sólidos do saneamento: processamento, reciclagem e disposição final. Rio de Janeiro: RiMa/ABES, 2001. cap.8, p.189-214.

Costa, M. S. S. de M.; Costa, L. A. de M., Sestak, M.; Olibone, D.; Sestak, D.; Kaufmann, A. V.; Rotta, S. R. Compostagem de resíduos da indústria de desfibrilação de algodão. Engenharia Agrícola, Jaboticabal, v.25, n.2, p.540-548, 2005.

Cravo, M. S.; Muraoka, T.; Giné, M. F. Caracterização química de compostos de lixo urbano de algumas usinas brasileiras. Revista Brasileira de Ciência do Solo, Campinas, v.22, n.3, p.547553, 1998.

EMBRAPA - Empresa Brasileira de Pesquisa Agropecuária Manual de métodos de análise de solo. 2.ed. Rio de Janeiro: CNPS, 1997. 212p.

Ferreira, A. C.; Andreoli, C. V.; Lara, A. I. Riscos associados ao uso do lodo de esgoto. In: Uso e manejo do lodo de esgoto na agricultura. Rio de Janeiro: PROSAB, p.29-33, 1999.

Helyar, K. R. Nitrogen cycling and soil acidification. Journal Australian Institute of Agricultural Science, Sidney, v.42, p.217221, 1976.

Jeevan Rao, K.; Shantaram, M. V. Effect of urban solid wastes on cadmium, lead and zinc in contaminated soils from southwest Poland. Journal of Environmental Biology, Muzaffarnagar, v.17, n.1, p.25-32, 1996.

Katz, N.; Chaves, A.; Pellegrino, J. A simple device for quantitative stool thick-smear technique in Schistosoma mansoni. Revista do Instituto de Medicina Tropical de São Paulo, São Paulo, v.14, n.6, p.397-400, 1972.

Lopes, J. C.; Ribeiro, L. G.; Araújo, M. G.; Beraldo, M. R. B. S. Produção de alface com doses de lodo de esgoto. Horticultura Brasileira, Brasília, v.23, n.1, p.143-147, 2005.

Malta, T. S. Aplicação de lodos de estações de tratamento de esgotos na agricultura: estudo do caso do município de Rio das Ostras, RJ. Rio de Janeiro: Fundação Oswaldo Cruz/ Escola Nacional de Saúde Pública, 2001. 68 p. Dissertação Mestrado

Martins, A. L. C.; Bataglia, O. C.; Camargo, O. A.; Cantarella, H. Produção de grãos e absorção de $\mathrm{Cu}$, Fe, Mn e Zn pelo milho em solo adubado com lodo de esgoto, com e sem calcário. Revista Brasileira de Ciência do Solo, Viçosa, v.27, n.3, p.563-574, 2003.

Melo, W. J., Marques, M. O., Melo, V. P. O uso agrícola do biossólido e as propriedades do solo. In: Tsutiya, M. T., Comparini, J. B., Alem Sobrinho, P., Hespanhol, I., Carvalho, P. C. T., Melfi, A. J., Melo, W. J., Marques, M. O. (ed.). Biossólidos na agricultura. São Paulo: Companhia de Saneamento Básico do Estado de São Paulo, 2002. p.289-363.

Moreira, F. M. S.; Siqueira, J. O. Microbiologia e bioquímica do solo. Lavras: UFLA, 2002. 626p.

Mulchi, C. L.; Adamu, C. A.; Bell, P. F.; Chaney, R. L. Residual heavy metal concentrations in sludge-amended coastal plain soils: I. Comparason of extractants. Communications in Soil Science and Plant Analysis, London, v.22, p.919-941, 1991.

Nascimento, C. W. A.; Barros, D. A. S.; Melo, E. E. C.; Oliveira, A. B. Alterações químicas em solos e crescimento de milho e feijoeiro após aplicação de lodo de esgoto. Revista Brasileira de Ciência do Solo, Viçosa, v.28, n.2, p.385-392, 2004. 
Oliveira, de J. A.; Cambraia, J.; Cano, M. A. O.; Jordão, C. P. Absorção e acúmulo de cádmio e seus efeitos sobre o crescimento relativo de plantas de aguapé e de salvínia. Revista Brasileira de Fisiologia Vegetal, Campinas, v.13, n.3, p.329-341, 2001.

Pereira, B. F. F. Potencial fitorremediador das culturas de feijão-de-porco, girassol e milho cultivados em Latossolo Vermelho contaminado com chumbo. Campinas: IAC, 2005. 68p. Dissertação Mestrado

Pires, A. M. M. Extração de metais pesados fitodisponíveis em solos tratados com lodo de esgoto: uso de ácidos orgânicos. Jaguariúna: Embrapa Meio Ambiente, 2005. 5p. Comunicado Técnico, 28

Rangel, O. J. P.; Silva, C. A.; Bettiol, W.; Guilherme, L. R. G.; Dynia, J.F. Acúmulo de $\mathrm{Cu}, \mathrm{Mn}, \mathrm{Ni}$, Pb e Zn em Latossolo Vermelho adubado com fontes de lodo de esgoto e cultivado com milho. Ciência Agrotécnica, Lavras, v.28, n.1, p. 15-23, 2004.

Silva, F. C. da; Boaretto, A. E.; Berton, R. S. Zotelli, H. B.; Pexe, C. A.; Mendonça, E. Cana-de-açúcar cultivada em solo adubado com lodo de esgoto: nutrientes, metais pesados e produtividade. Pesquisa Agropecuária Brasileira, Brasília, v.33, n.1, p.1-8, 1998.

Silva, J. E.; Resck, D. V. S.; Sharma, R. D. Alternativa agronômica para o biossólido produzido no Distrito Federal: I. efeito na produção de milho e na adição de metais pesados em latossolo no Cerrado. Revista Brasileira de Ciência do Solo, Viçosa, v.26, n.2, p.487-495, 2002.
Soares, F.; Amaral Sobrinho, N. M. B.; Mazur, N. Influência de diferentes manejos agrícolas na distribuição de metais pesados no solo e em plantas de tomate. Revista Brasileira de Ciência do Solo, Viçosa, v.26, n.2, p.535-542, 2002.

Soccol, T. V.; Paulino, R. C. Riscos de contaminação do agroecossistema com parasitos pelo uso do lodo de esgoto. In: Bettiol, W.; Camargo, O. A. Impacto ambiental do uso agrícola do lodo de esgoto. Jaguariúna: Embrapa Meio Ambiente, 2000. 312p.

Sopper, W. E. Municipal sludge use in land reclamation. New York: Lewis publishers, 1993. 163p.

Tedesco, M. J.; Gianello, C.; Bissani, C. A.; Bohnen, H.; Volkweiss, S. J. Análise de solo, plantas e outros materiais. 2. Ed. Porto Alegre: Departamento de Solos. UFRGS. 174p. 1995. Boletim Técnico, 5

Trannin, I. C. de B.; Siqueira, J. O.; Moreira, F. M. de S. Avaliação agronômica de um biossólido industrial para a cultura do milho. Pesquisa Agropecuária Brasileira, Brasília, v.40, n.3, p.261-269, 2005.

Valsecchi, G.; Giglioti, C.; Farini, A. Microbial biomass, activity, and organic matter accumulation in soils contaminated with heavy metals. Biology and Fertility of soils, Berlin, v.20, p.253-259, 1995. 